\title{
O PAPEL DOS GESTORES DE RH DE ESTABELECEDORES DE NOVOS MODELOS DE CONVIVÊNCIA NAS ORGANIZAÇÕES ATRAVÉS DA MEDIAÇÃO DE CONFLITOS GERACIONAIS
}

\author{
THE ROLE OF HR MANAGERS IN ESTABLISHING NEW MODELS OF \\ COEXISTENCE IN ORGANIZATIONS THROUGH THE MEDIATION OF \\ GENERATIONAL CONFLICTS
}

\author{
Renan Gomes de Moura* \\ renangmoura@gmail.com \\ Paloma de Lavor Lopes**, *** \\ palomalavor@gmail.com \\ * Universidade do Grande Rio, Rio de Janeiro/RJ, Brasil \\ ** Centro Universitário Geraldo di Biase,Volta Redonda/RJ, Brasil \\ *** Faculdade Sul Fluminense, Volta Redonda/RJ, Brasil
}

\section{Resumo}

Em meio a diferentes profissionais, cada um com seu modo de pensar sobre o trabalho e forma de trabalhar, - conflito facilmente instala-se num ambiente organizacional gerando choques de ideias e consequentemente perda da produtividade. Nesse momento o gestor de Recursos Humanos possui um papel fundamental, o de mediador. Esse trabalho tem por objetivo geral evidenciar o papel do gestor de Recursos Humanos diante de conflitos geracionais. Para tanto, foi realizada tanto uma pesquisa bibliográfica quanto uma pesquisa de campo visando evidenciar os conflitos existentes em uma organização. Os resultados alcançados por esse trabalho permitiram analisar que os conflitos entre Geração Baby Boomers, Geração X e Geração $Y$, podem ser minimizados a partir do momento que os gestores modifiquem seu modo de lidar com os diferentes profissionais, entendendo as causas dos conflitos para chegar à resolução mais assertiva possível.

Palavras-chave: Conflito; Gestor de Recursos Humanos; Geração Baby Boomers; Geração X, GeraçãoY;

\begin{abstract}
Amid different professionals, each with their way of thinking about work and way of working, the conflict easily installs in an organizational environment shocks generating ideas and consequently loss of productivity. Right now the human resources manager has a key role, that of mediator. This work has the objective to highlight the role of human resources manager before generational conflicts. Therefore, we performed a literature both as research field aiming to highlifht the conflicts in a organization. The results achieved by this work helped analyze the conflicts between Generation Baby Boomers, Generation X and Generation Y, can be minimized from the time that managers modify their approach with different professionals, understanding the causes of conflict to reach more assertive resolution possible.

Keywords: Conflict; Human Resources Manager; Generation Baby Boomers; Generation X; Gereration Y.
\end{abstract}




\section{INTRODUÇÃO}

Com o decorrer do tempo, o ambiente organizacional passou por várias mudanças, entre elas podemos destacar a mudança no comportamento humano, no seu modo de agir e pensar no ambiente profissional.

As pessoas são diferentes uma das outras, cada uma faz parte de uma determinada época e geração marcada por pensamentos e ideologias diferentes que podem caracterizar o modo de cada um agir no ambiente de trabalho. Essa diversidade entre as gerações, caso não seja bem administrada, em determinados momentos podem gerar conflitos de ideias, que podem ser prejudiciais ao andamento do trabalho e também para as relações interpessoais dos profissionais. Os conflitos no trabalho nem sempre podem ter sua origem na organização, na maioria dos casos mesmo que isso não seja diretamente percebido pelas partes envolvidas pode ser causado por motivos ligados ao seu modo de vida.

A incompatibilidade de pensamentos e ideias que gera o conflito entre os humanos é algo que sempre vai existir, visto que as pessoas possuem características únicas de comportamento, no entanto no ambiente profissional essa situação pode ser minimizada a partir do momento que o gestor saiba ser um mediador de conflitos.O gestor de Recursos Humanos possui papel fundamental nessa mediação, além de saber identificar os diferentes comportamentos dos profissionais de cada geração, torna-se necessário que entenda as causas sociológicas desses conflitos para que seja alcançada a melhor solução para o problema a ser tratado e assim evitar a existência de um ambiente organizacional hostil e prejuízos ao desenvolvimento do trabalho de forma geral.

Diante do exposto, justifica-se a importância de abordar o tema conflitos entre as gerações devido às organizações atuais possuírem em seu quadro funcional uma grande diversidade de profissionais pertencentes a diferentes gerações e, portanto, com comportamentos profissionais diferentes possibilitando a existência de conflitos, além disso, grande parte dos gestores ainda possuem dificuldades de mediar esses conflitos.

O problema de estudo deste artigo levanta a seguinte questão: A identificação dos diferentes comportamentos humanos no trabalho pelo gestor de Recursos Humanos pode auxiliar na mediação 
de conflitos entre as gerações Baby Boomers, X e Y?Com base nessa problemática acredita-se que os conflitos geracionais poderão ser minimizados na medida em que o gestor de Recursos Humanos identifica as diferenças comportamentais desses profissionais e realiza ações adequadas a cada tipo de situação. Este artigo propõe-se em evidenciar o papel do gestor de Recursos Humanos diante de conflitos geracionais, além de apresentar as possíveis causas desses conflitos, diferenciar os comportamentos dos profissionais das gerações Baby Boomers, X e Y e apresentar os aspectos sociológicos dos conflitos.

\section{1- CONFLITOS ORGANIZACIONAIS}

No ambiente organizacional as relações são inevitáveis e na maioria dos casos os conflitos também. Segundo Robbins, (2010, p. 437) o conflito pode ser definido como o "processo que tem início quando alguém percebe que outra parte afeta, ou pode afetar, negativamente alguma coisa que considera importante". Na visão de Weil (2004, p.127) pode-se entender que conflito se trata de "uma situação de tensão, resultado do atrito entre forças aparentemente opostas ou incompatíveis, tais como opiniões, atitudes, hábitos, necessidades e desejos". Para Martinelli e Almeida (2011, p.46) o conflito está relacionado à frustração e pode ser tanto construtivo quanto destrutivo, de acordo com a forma que é conduzido. Desse modo, em uma organização em que diversas pessoas de diferentes gerações precisam se relacionar entre si, existe a possibilidade de que situações conflituosas ocorram, gerando consequências negativas.

Por outro lado, os conflitos quando bem conduzidos podem ser benéficos para à construção do conhecimento e para toda a organização de modo geral. Para Robbins, (2010, p.445) o conflito pode melhorar a eficácia dos grupos e tornam-se construtivos quando incentivam a criatividade e a inovação e afirma que:

As evidências sugerem que o conflito pode melhorar a qualidade no processo decisório por permitir que todos os pontos de vista sejam avaliados, especialmente os não usuais ou os que são defendidos por minorias. O conflito é um antídoto contra o pensamento do grupo. (ROBBINS et. al. 2010, p.445) 
Para que uma organização ganhe em competência, habilidades e conhecimentos torna-se necessário que os gestores sejam bons mediadores de situações conflituosas surgidas entre os grupos de trabalho e transforme o que poderia ser destrutivo em construtivo. No entanto é fundamental entender as diferenças individuais e grupais dos envolvidos assim como seu comportamento organizacional.

Para Andrade et. al. (2011, p.45) os conflitos sociais são o resultado dos comportamentos divergentes e podem resultar em crimes dos que não se conformaram com os meios normais de evolução e resolução. Os conflitos quando não tratados adequadamente podem levar a consequências negativas tanto para o indivíduo quanto para a sociedade com a qual convive. $\mathrm{O}$ conflito pode ser considerado um fenômeno social, natural da existência humana, e pode apresentar diversos aspectos os quais podem afetar suas relações. De acordo com Barros (2009, p. 78), os conflitos podem ter cinco principais causas, relacionadas aos seguintes aspectos: de valor, de estrutura, de competição, de relacionamento e de informação.

Os aspectos competitivos são os relacionados à competição por algo, seja uma posição, dinheiro, conhecimento entre outros. A competição pode levar a uma significativa origem de conflitos e por diversas vezes acontece de forma natural, de acordo com Barros (2004, p.80), apesar de homem buscar a socialização, constitutivamente, procura demonstrar que é melhor que o outro.

Os aspectos interpessoais referem-se à forma dos indivíduos se relacionarem uns com os outros, o modo como o ser humano julga o outro sem conhecê-lo o suficiente pode prejudicar a interatividade entre eles. Assim como os aspectos interpessoais, os aspectos relacionados ao valor também podem gerar conflitos. O valor aqui mencionado refere-se aos princípios que norteiam hábitos e atitudes do ser humano. Quando não há respeito pelos princípios do outro, torna-se mais difícil administrar uma situação conflituosa.

\section{2- GERAÇÕES X CONFLITOS}

Nos últimos anos o mercado de trabalho modificou-se consideravelmente, tanto em aspectos sociais e econômicos quanto na força de trabalho que o compõe. A diversidade em relação ao gênero, idade, raça entre outras características biográficas, está cada vez mais presente nas 
organizações atuais, e as diferenças no seu estilo de trabalho também se tornam evidentes. Essas diferenças tendem a tornarem-se "brechas" para o início de conflitos, visto que cada pessoa ou grupo desenvolve sua própria forma de trabalho, que nem sempre é a mesma adotada pelos demais e pode causar resistências e oposições na outra parte, conforme reforça Carvalhal:

(...) grupos que realizam tarefas diferentes e se relacionam com o ambiente começam a desenvolver maneiras únicas de pensar sobre o mundo. Eles passam a ter seu próprio jargão, objetivos e modo de trabalhar. Por isso tendem a desenvolver uma visão singular sobre as suas demandas e uma visão estereotipada sobre as demais. (CARVALHAL, 2009, p. 27)

Atualmente, o mercado de trabalho é formado pelas gerações que ainda estão presentes nas organizações, são elas a geração Baby Boomers, geração X e geração Y, que possuem características diferentes entre si. O termo geração pode ser entendida de acordo com Mannheim (1993, p.5 apud Cordeiro et. al. 2012) como parte do processo histórico que indivíduos da mesma idade-classe compartilham e é constituída pela presença de eventos que quebram a continuidade histórica e a vivência desse momento por membros de um grupo etário durante seu processo de socialização, predispondo-os a certos modos de pensar e experiências. Segundo Cordeiro et. al. (2012, p. 5) a data de nascimento em si não define o conceito de geração.

Estas características comuns das diferentes gerações influenciam o modo de ser e de viver das pessoas nas sociedades e é este conjunto de comportamentos e valores que diferenciam uma geração de outra. Um dos desafios da sociedade é permanentemente compreender e adaptar-se a estas novas gerações e a todas as mudanças geradas. (VASCONCELOS et. al. 2012, p. 229)

No entanto, também se tratam de relações sujeitas a conflitos que podem ser ocasionados pelas diferenças no estilo profissional que cada um apresenta devido às características da geração a qual pertencem. De acordo com Silva e Moura (2011, p. 6 apud Assis et. al. 2012) as diferenças entre as gerações tiveram mais destaque com a evolução da tecnologia, comunicação e interatividade. Para Robbins (2010, p. 439), os conflitos nem sempre tendem a ser saudáveis no ambiente de trabalho quando tratados inadequadamente, e acrescenta que:

(...) de modo geral, os conflitos no local de trabalho não são produtivos, visto que tomam o tempo que deveria ser dedicado às tarefas ou à interação 
com os clientes, sem contar que provocam sentimentos de mágoa e de raiva que perduram, muitas vezes, após os conflitos terem acabado. (ROBBINS, 2010 p.439)

Desta forma, torna-se necessário evidenciar que os conflitos entre gerações é algo inevitável, visto que cada vez mais fatores como a globalização e as constantes mudanças em diversas áreas, inclusive no ambiente organizacional, influencia de modo direto ou indiretamente as relações e os comportamentos das pessoas nas organizações, fazendo com que pensamentos divergentes surjam entre os grupos de trabalho. Entender cada geração é uma forma de começar a traçar possíveis meios de mediar e minimizar conflitos.

\section{1- Geração Baby Boomers, Gerações X, Y e Z}

São considerados Baby Boomers, os nascidos entre 1945 e 1963, apesar da divergência de autores sobre essas datas. Segundo Conger (1998, p. 3 apud Santos et. al. 2011), essa geração é composta por pessoas que presenciaram a guerra e a luta das feministas pelos seus direitos. Foram criadas para seguir regras de acordo com os padrões de disciplina e obediência e educadas com rigidez. Para Boog (2008) essa geração se encontra no topo da hierarquia das empresas, ou ocupam vagas de nível sênior nas organizações. São profissionais que "vestem a camisa da empresa", voltados aos resultados e que não se preocupam com a qualidade de vida e sim com o status e poder. Essa geração considera liderança como uma forma de controlar ou comandar pessoas. Os Baby Boomers têm dificuldade em lidar com tecnologia digital, visto que aprenderam a utilizá-las depois de adultos.

Para Kanaame (1999, p. 3 apud Santos et. al. 2011) os Baby Boomers levam em consideração a empregabilidade e a preservação do emprego pelo maior tempo possível. Essa geração aplica suas competências para conseguir uma garantia de segurança no futuro, geralmente passaram a maior parte de suas vidas em um só emprego. Os profissionais considerados pertencentes à Geração X segundo Oliveira (2009), são aqueles nascidos entres 1960 e 1980, enquanto Elgemann (2009, p.5 apud Santos et.al. 2009) considera entre 1964 a 1977. Essas pessoas vivenciaram momentos de grandes mudanças tanto no aspecto social, econômico e político sendo que essas mudanças ajudaram a traçar características dessa geração. 
Oliveira (2009) destaca que essa geração foi totalmente influenciada por programas de televisão, tanto no que diz respeito à educação, quanto à rotina familiar e que essa influência também envolveu um aumento dos apelos consumistas, reordenando o modo de viver e agir das pessoas. No ambiente organizacional essa geração em geral aprecia um ambiente mais informal e com hierarquia menos rígida, porém necessitam de regras no trabalho. Além disso, são caracterizados como resistentes a mudanças e apresentam certa insegurança em relação à perda do emprego. De acordo com Lombardia (2008, p. 4) as pessoas dessa geração "são conservadores, materialistas e possuem aversão a supervisão. Desconfiam de verdades absolutas, são positivistas, autoconfiantes, cumprem objetivos e não os prazos, além de serem muito criativos".

A Geração Y, assim como as anteriores também diverge sobre a data exata de nascimento, de acordo com alguns especialistas no assunto, essa geração é composta por jovens nascidos entre as décadas de 80 e 90. Para Carvalho et. al. (2012) essa geração nasceu a partir dos anos 70 e inicio da década de 1980. Os profissionais que compõem essa geração cresceram em contato com as tecnologias que surgiam na mesma época, fazendo com que desenvolvessem competências na área, o que era um diferencial em comparação com os profissionais das gerações Baby Boomers e X. Segundo Maldonado (2005, p. 5 apud Andrade et. al. 2012), enquanto as gerações anteriores se adaptaram às tecnologias, essa geração já nasceu nesse contexto e alguns estudos comprovam que as pessoas habituadas com ferramentas virtuais desenvolvem um sistema cognitivo diferente.

Essa geração de acordo com Oliveira (2010, p.5 apud Andrade et. al. 2012) é movida por desafios e interesse em rápido crescimento profissional. São caracterizados por valorizar a autonomia e otimismo, buscam o equilíbrio entre trabalho e vida pessoal, são flexíveis, competitivos, individualistas, impacientes e demonstram indiferença em relação à autoridade, buscam serem tratados igualmente, se preocupam com a carreira e buscam constantemente novas oportunidades e desafios. Outra característica segundo Oliveira (2010, p.5 apud Andrade et. al. 2012) é a abertura a mudanças, assim como o processo inverso, o de implantar mudanças nos ambientes que se inserem. Portanto, são profissionais que em geral buscam por constante inovação.

A geração $\mathrm{Z}$ é a mais recente de todas, seus membros nasceram na era da Informação e ainda não estão atuando no mercado de trabalho, de acordo com Andrade et. al. (2012, p.6) são considerados desta geração aqueles nascidos em meados dos anos 90. Serrano (2010) e Wielsel 
(2010) caracterizam os membros dessa geração como fortemente conectados a tecnologia de informação, diferenciando-os das demais gerações, estão sempre sintonizados com o mundo por meio de recursos móveis e não apenas por um computador de mesa, quando o conceito de grupo passa a ser virtual. São dinâmicos, críticos, precoces e tendem a ser ecologicamente corretos.

Os conflitos organizacionais podem se originar de diversas formas. De acordo com Martinelli e Almeida (2011, p. 59), cada área da organização desenvolve objetivos e procedimentos de acordo com sua missão, dessa forma, inevitavelmente algum atrito ocorrerá entre essas áreas devido as diferenças de prioridades. Já para Barros (2009, p.76), o conflito tem origem em um relacionamento negativo, e que existem aspectos do relacionamento que colocam os indivíduos em situações de oposição de interesses, gerando claramente um conflito. Os conflitos existentes entre os profissionais de diferentes gerações podem ter causas distintas, mas que levam a consequências negativas como a improdutividade. Uma das causas de conflitos entre as gerações no ambiente organizacional segundo Stefenoni (2010, p. 02 apud Gualdi et. al. 2011) é o avanço tecnológico, que modificou a estrutura das empresas e o modo de trabalho dos profissionais, ressalta que:

A geração $X$ é composta por profissionais mais experientes. E a Y compõese de pessoas entre 20 e 30 anos. Como a geração $\mathrm{Y}$ tem o entusiasmo nas mudanças e inovações, (...) ficou mais fácil para eles se adaptarem ao novo modelo de organizações, pois estas exigem cada vez mais. Contudo o grupo dos mais antigos na empresa só tem duas alternativas: entrar de cabeça na inovação, ou pedir demissão (...) como a diferenciação na maneira de pensar é grande gera-se o conflito entre os jovens talentosos que são nascidos a partir de 1978 e os profissionais mais experientes, da geração X (19641977). (STEFENONI, 2010, p.02 apud GUALDI et. al. 2011).

De acordo com Banov e Fidelis (2001, p.174) uma avaliação precoce das causas do conflito pode abreviar o tempo de exposição das pessoas em compreender o caráter do conflito e tornar a resolução eficaz.

\section{3- GESTOR DE RECURSOS HUMANOS: UM MEDIADOR DE CONFLITOS}

Os desafios em relação à gestão de pessoas fazem parte do cotidiano desses gestores, entre eles está lidar com as diferenças entre os profissionais pertencentes às diferentes gerações, que tendem a ocasionar conflitos organizacionais. Segundo Spector (2010, p.526) "um dos maiores 
desafios para o futuro da liderança nas organizações refere-se à crescente diversidade no local de trabalho". Segundo Chiavenato (2009, p.127) a Administração de Recursos Humanos envolve algumas dificuldades visto que lida com pessoas, e estas são complexas, diversificadas e variadas entre si. Chiavenato ainda ressalta que "esses recursos são importados do ambiente para dentro da organização, crescem, desenvolvem-se, mudam de atividade, de posição e de valor". As pessoas são diferentes entre si e mutáveis no ambiente organizacional e os gestores precisam aprender a lidar com essas mudanças. Robbins completa ressaltando que:

Os administradores precisam modificar sua filosofia de tratar todo mundo de modo igual, reconhecendo as diferenças e respondendo a elas de maneira a assegurar a retenção dos funcionários e uma maior produtividade, sem que se cometa qualquer discriminação. (ROBBINS, 2010, p. 39).

Os conflitos geracionais merecem atenção especial principalmente por parte dos gestores de Recursos Humanos, aqueles que estão diretamente ligados ao que diz respeito às relações humanas na organização. Segundo Banov e Fidelis (2011, p. 174) a administração de conflitos é uma virtude indispensável para o administrador de pessoas, e completam ressaltando que "os conflitos são inevitáveis, o gestor de pessoas deve prevê-los, conhecer as possíveis soluções, analisar as condições que o provocam e partir ao encontro da sua solução de maneira profilática". Diante de um processo de conflito, esse profissional pode desempenhar o papel de mediador, auxiliando os envolvidos na administração do problema. De acordo com Barros (2009, p. 77) o mediador é um negociador interferindo em um conflito entre duas partes em que há um interesse maior e como mediador tentará fazer com que as partes alcancem sua meta. Já Martinelli e Almeida (2011, p. 73) destacam que:

O mediador não resolve o problema nem impõe uma solução. Sua função é ajudá-los a buscar o melhor caminho e fazer com que esteja de acordo depois de encontrada a solução. (...) O maior interesse do mediador é ajudar as partes nas questões de comunicação. (MARTINELLI E ALMEIDA, 2011 p.73).

Como mediador de conflitos o gestor de RH precisa agir de forma proativa, evitando que o problema em questão alcance maiores proporções, conforme sugere Gil, destacando que esse profissional deve ter: 
(...) comportamento proativo em face dos problemas, procurando antecipar as soluções para aqueles que ocorrem periodicamente, buscando acabar com eles ou minimizar seus efeitos negativos, evitar trabalhar na base da crise permanente, do "remendo" ou tratamento reativo aos problemas (deixar acontecer para depois agir) (GIL, 2010, p. 68).

Os gestores precisam conscientizar-se que entender as causas de situações conflituosas é uma forma de ajudar na realização dos objetivos organizacionais. Segundo Andrade et al (2011, p.27) a empresa deve buscar formas de alcançar seus objetivos tratando os conflitos e destaca que:

Tratando-se de três gerações de trabalho com características diferentes entre si, o gestor de Recursos Humanos desempenha um papel fundamental na relação entre essas pessoas, já que a possibilidade de conflitos entre elas tende a existir. Para que os conflitos na organização sejam minimizados é fundamental que sejam postas em práticas ações que propiciem resultados positivos. Para Banov e Fidelis (2011, p. 174):

O bom relacionamento com as pessoas é percebido por meio de ações concretas por parte do gestor que enfrenta os conflitos de maneira integrada com os envolvidos. Atitudes preventivas visam, através da comunicação aberta entre gestor e funcionário, reduzir as possibilidades de conflitos e suas consequências negativas. (BANOV; FIDELIS, 2011, p. 174).

Na busca de uma forma para que o gestor de Recursos Humanos atue como um mediador de conflitos entre gerações, sugere-se o método Pisar e Pesar. Trata-se de um método para a resolução de conflitos proposto pelo professor, educador e psicólogo francês Pierre Weil, (1924-2008). Para Weil (2004, p.127) conflito pode ser conceituado como uma situação de tensão, resultado do atrito entre forças aparentemente opostas ou incompatíveis, tais como opiniões, atitudes, hábitos, necessidades e desejos.

Para que situações de incompatibilidade entre as pessoas possam ser minimizada, o autor propôs o método Pisar e Pesar, como forma de mediar conflitos, tem como base o seguinte: a palavra PISAR a partir da sua primeira letra forma cinco palavras: Percepção, Imaginação, Sentimento, Ação e Reação. O PISAR representa na vida das pessoas passos costumeiros diante de uma situação, por exemplo: nossa percepção (P) nos apresenta o que estamos percebendo de um fato, nossa imaginação (I) nos diz como interpretamos esse fato, nosso sentimento (S) diz respeito 
sobre o qual sentimento advém da nossa imaginação, nossa ação (A) apresenta como agimos diante desse sentimento e nossa reação (R) apresenta a reação da outra pessoa a partir da nossa ação. Segundo Nery (2003) para intervir nesse processo de conflito torna-se necessário transformar o PISAR em PESAR. Assim como PISAR, o PESAR é uma palavra formada por cinco palavras: Percepção, Estimativa, Sentimento, Ação e Reação. A estimativa faz toda a diferença na resolução de um conflito. Segundo Weil, (2004, p.141) "o PESAR segue a mesma sucessão de eventos psicológicos do PISAR, mas com a finalidade específica: intervir num PISAR conflitivo, a fim de transformar o conflito numa relação humana harmoniosa".

\section{5- METODOLOGIA}

Para chegar a um conhecimento em sua profundidade torna-se necessário ir além dos conhecimentos empíricos, nesse sentido, a pesquisa bibliográfica é uma das bases para a construção de um conhecimento científico. Segundo Manzo (1971, p.166 apud Lakatos e Marconi, 2010) a bibliografia "oferece meios para definir, resolver, não somente problemas já conhecidos, como também explorar novas áreas onde os problemas não se cristalizaram suficientemente". Para reforçar o conhecimento obtido com a pesquisa bibliográfica, torna-se relevante o uso da pesquisa de campo, sendo que nesse estudo adotou-se o método descritivo analítico, que de acordo com Lakatos e Marconi (2010, p.170) consiste na investigação de pesquisa empírica com o objetivo de delinear ou analisar características de fatos ou fenômenos, avaliar programas ou o isolamento de variáveis.

Foram elaborados questionários com perguntas fechadas que foram aplicados a colaboradores e supervisores da empresa, com idades entre 20 a 65 anos, ou seja, profissionais pertencentes às diferentes gerações que se encontram no mercado (Baby Boomers, X e Y).

A escolha pela área comercial de uma empresa do setor alimentício se deu pela importância desse setor, que é o responsável direto pela venda de toda a produção da empresa. O setor é um dos mais pressionados pela corporação, pois, a queda nas vendas traz consequências diretas a outros setores, como produção, que sem pedidos fica com mercadoria retida e não havendo saída tende a perecer e consequentemente a empresa perderá lucro afetando diretamente setores administrativos (financeiro, recursos humanos, logística, etc), pois tendem a ter redução de custos e quadro 
funcional. Portanto, a área comercial pode ser considerada base estratégica da organização e a ocorrência de conflitos pode afetar todo o resultado. Foi utilizada a metodologia de análise de conteúdo, passando pelas três fases de Bardin (1977): a pré-análise; a exploração do material; e o tratamento dos resultados, a inferência e a interpretação.

\section{6- APRESENTAÇÃO E ANÁLISE DE RESULTADOS}

Após análise dos questionários aplicados pode-se chegar aos seguintes resultados em relação aos supervisores entrevistados: Aqueles que estão entre 20 a 34 anos buscam rápido crescimento profissional, comprovando umas das características da Geração Y, para isso qualificam-se constantemente, sendo que a maioria cursa ou já possui nível superior de ensino, o que garantiu que alcançassem um cargo de liderança rapidamente.

GRÁFICO 1- Relação Idade X Escolaridade X Tempo De Liderança

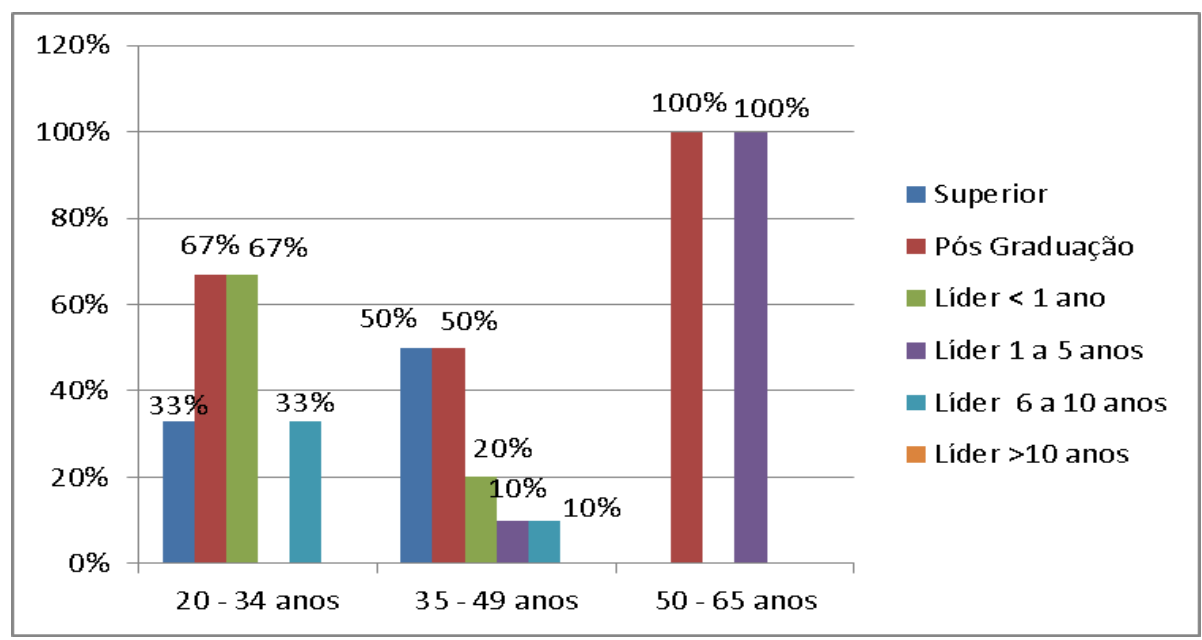

Fonte: Pesquisa de Campo.

Enquanto os supervisores de 35 a 49 anos, que se encaixam na Geração X, estão equilibrados em relação à qualificação em comparação aos da Geração Y, no entanto os profissionais Y estão em vantagem em relação à liderança, 67\% são lideres a menos de um ano contra $20 \%$ de profissionais $\mathrm{X}$ que também possuem o mesmo tempo de liderança, enquanto a liderança que está com idade entre 50 a 65 anos é composta apenas por 1 supervisor e este é líder entre 1 a 5 anos. 
Esse dado revela que tanto Geração $\mathrm{X}$ quanto a $\mathrm{Y}$ disputa diretamente melhores cargos, o que tende a gerar conflitos na relação profissional. O supervisor que está na faixa de 50 a 65 anos possui curso de pós-graduação, indicando que a busca pela qualificação se fez necessária com as mudanças ocorridas ao longo do tempo no ambiente corporativo. Outro ponto relevante é que todos os supervisores são do sexo masculino e 90\% casados, o que mostra que apesar dos avanços e conquistas da mulher no mercado de trabalho, ainda há certa dificuldade para que a diversidade no ambiente corporativo torne-se equilibrada. Em relação aos conflitos, os supervisores admitem enfrentar situações conflituosas, porém nenhum supervisor admitiu que cedeu em suas opiniões para que a empresa não fosse prejudicada, e a maioria acredita que os conflitos geram idéias e $20 \%$ preferem não entrar em conflitos para não prejudicar o clima no trabalho e consequentemente gerar inimizades.

Quando questionados sobre qual sua ação em relação a uma divergência, responderam que procurariam ouvir as partes para chegar a uma melhor decisão para todos, assim como 100\% responderam que diante de uma discussão entre seus liderados sua atitude é intervir e através do diálogo encontrar uma solução adequada a todos, porém os supervisores declararam que quando há uma discussão relacionada a uma decisão deles, $10 \%$ defenderiam sua opinião para convencer os outros a aderirem a sua idéia.

GRÁFICO 2- Relação Supervisores X Conflitos

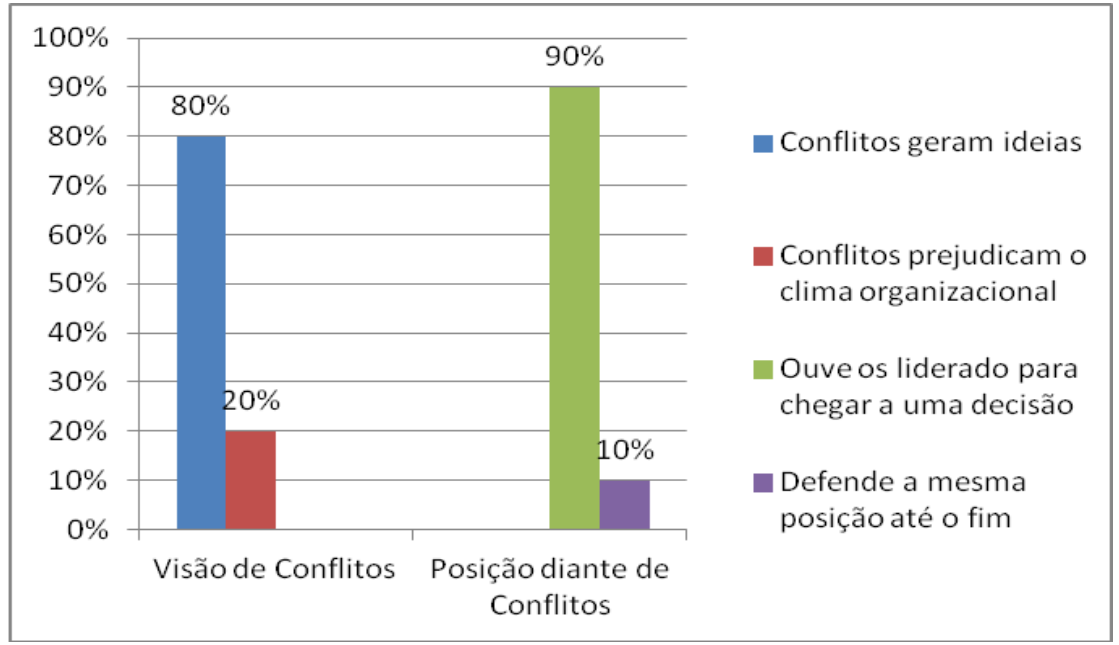

Fonte: Pesquisa de Campo 
Os gestores atribuem a maioria das dificuldades de relacionamentos com seus liderados está associada à resistência a mudanças e a falta de flexibilidade e apenas $20 \%$ a falta de comprometimento, sendo que sentem mais dificuldades de lidarem com pessoas entre 18 a 34 anos de idade, o que indica que independente da geração a maioria dos profissionais podem ter problemas no relacionamento por esse motivo, o que evidencia que se torna necessário à realização de ações pelos gestores para melhorar a aceitação às mudanças. Nenhum gestor atribuiu comunicação falha como um motivo que dificulta o relacionamento.

\section{GRÁFICO 3 - Fatores Que Dificultam A Relação Supervisor/Vendedor}

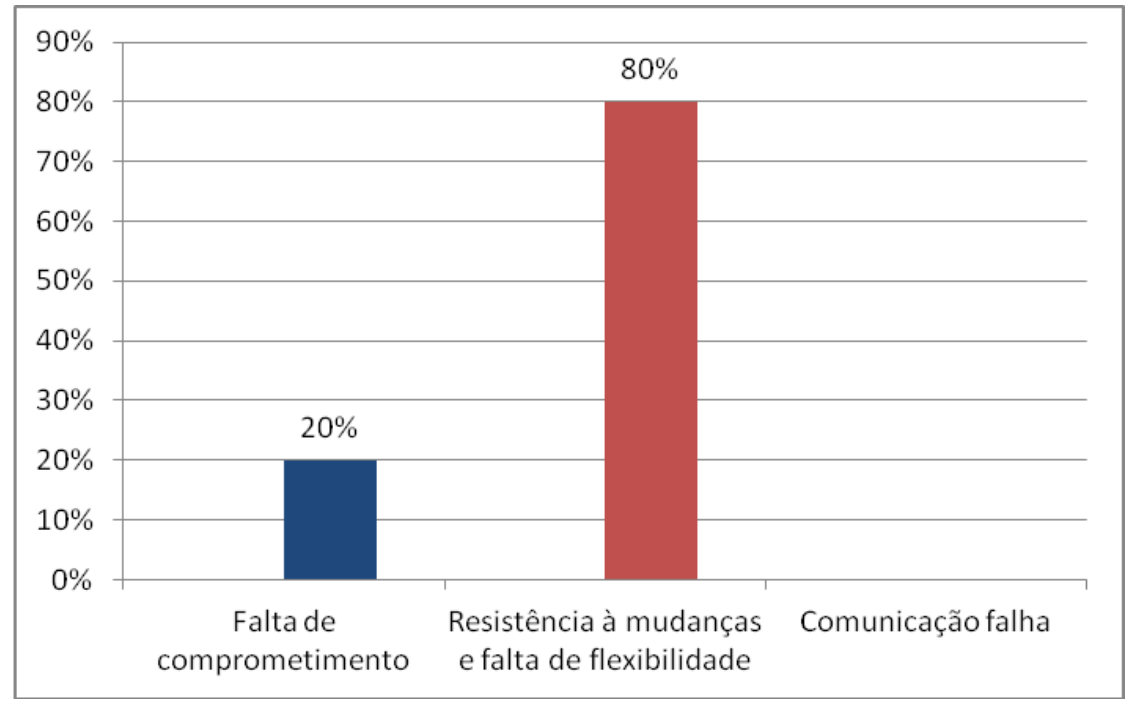

Fonte: Pesquisa de Campo

Em relação aos vendedores, observou- se que: a maioria possui curso superior, o que mostra que o mercado está exigindo cada vez mais pessoas preparadas independente do nível hierárquico e que os profissionais das gerações $\mathrm{Y}$ e $\mathrm{X}$ são os que mais buscam qualificação, apesar de que os que os vendedores da Geração Baby Boomers, de 5, 3 estão cursando ou possuem curso superior o que revela que apesar da idade possivelmente devido a competição no mercado de trabalho surgiu à necessidade de qualificarem-se.

GRÁFICO 4 - Nível De Escolaridade Dos Vendedores 


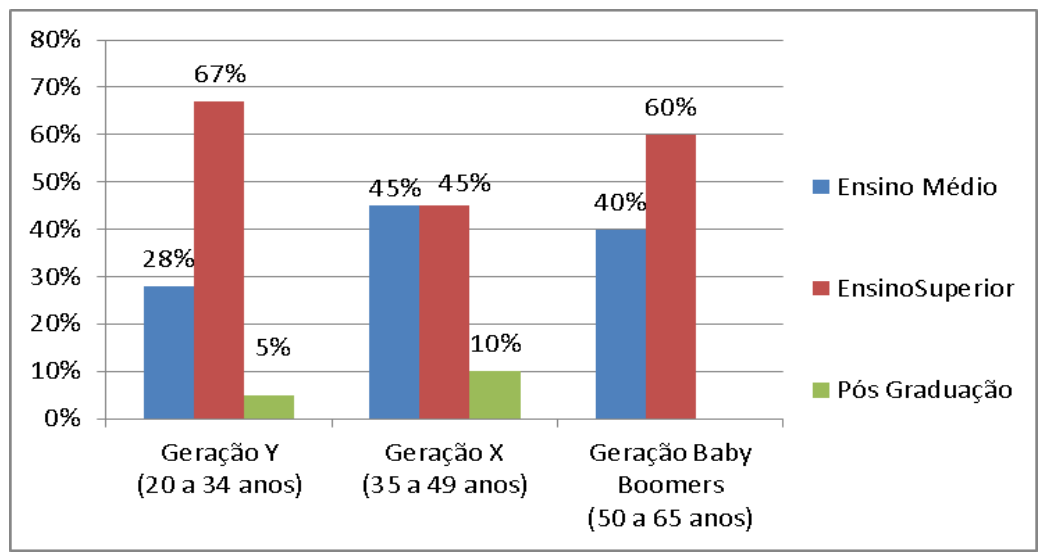

Fonte: Pesquisa de Campo.

Quanto aos conflitos, a maioria dos vendedores $\mathrm{Y}$ concorda que os mesmos são bons geradores de ideias, enquanto apenas $19 \%$ dos X pensam da mesma forma e nenhum Baby Boomers tem a mesma opinião sobre conflitos, estes preferem ceder em suas opiniões numa situação conflituosa e acreditam que conflitos prejudicam o clima organizacional. Percebe-se que os pensamentos entre as três gerações são bem diferentes e que a geração Y é a que demonstra ser mais flexível em relação a mudanças e a dos Baby Boomers a que concentra profissionais que buscam ficar longe de conflitos.

Entre a que mais ouve os argumentos dos outros numa situação conflituosa, a geração X é a que mais se destaca, seguido da geração Baby Boomers e Geração Y, sendo esta a que mais defende sua opinião até o fim numa discussão, enquanto nenhum Baby Boomers defende sua opinião durante um conflito, mais uma vez demonstrando que essa geração mesmo com as mudanças nas organizações ainda resiste em se envolver em assuntos mais estressantes como conflitos de ideias.

\section{GRÁFICO 5 - Relação Gerações X Conflitos}




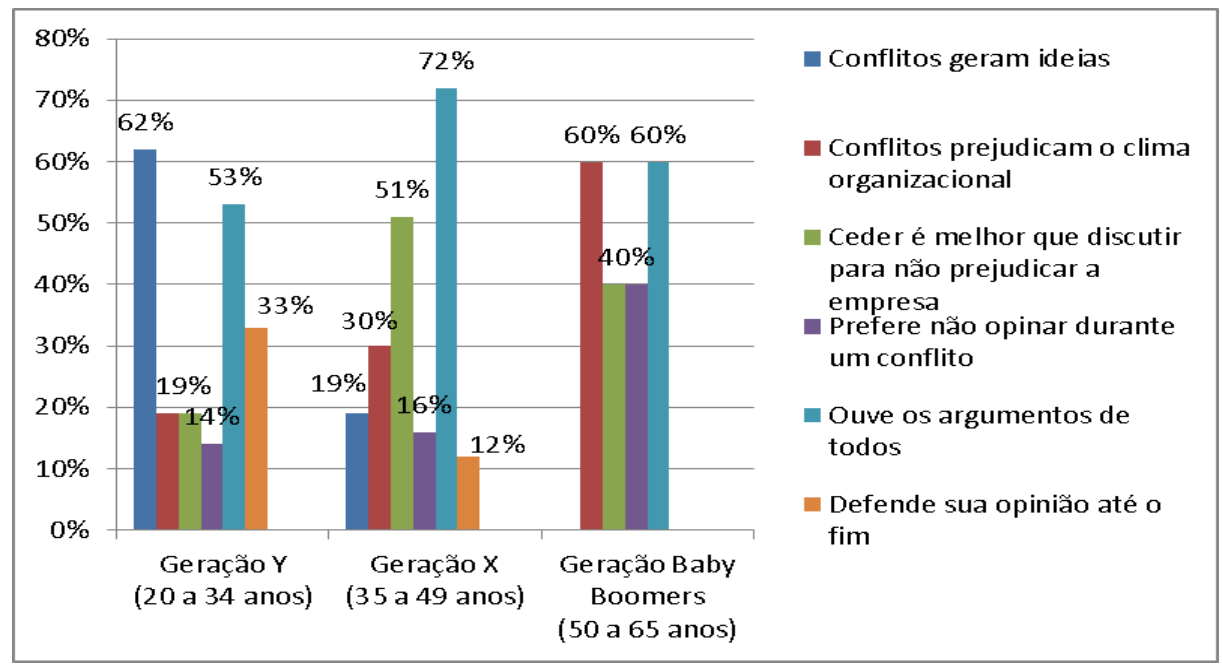

Fonte: Pesquisa de Campo.

No entanto, a maioria independente da geração, respondeu que confrontam as opiniões de seus supervisores quando acreditam que sua opinião está correta, e acreditam que todos têm direito de opinar, esse dado revela o que pode ser um possível estopim para o início de conflitos, enquanto os outros que não confrontam atribuem não fazer isso por respeito à autoridade e acreditam que se a pessoa tem poder, ela sabe o que está falando.

No entanto, diante de uma situação em que expressam alguma idéia a seu gestor e o mesmo diz "não", 43\% admite que se sente desapontado, mas procura entender o motivo da negativa e aperfeiçoar a idéia, esta opinião está mais concentrada entre os profissionais entre 20 a 34 anos, o que revela que esse grupo é persistente em seus objetivos, demonstrando uma das características da geração Y, que é a iniciativa profissional.

Quando questionados sobre o relacionamento com outros colegas de trabalho com idades diferentes observa-se que conforme a idade aumenta a preferência por trabalhar com pessoas da mesma idade também aumenta.

GRÁFICO 6- Preferência De Relacionamento No Trabalho 


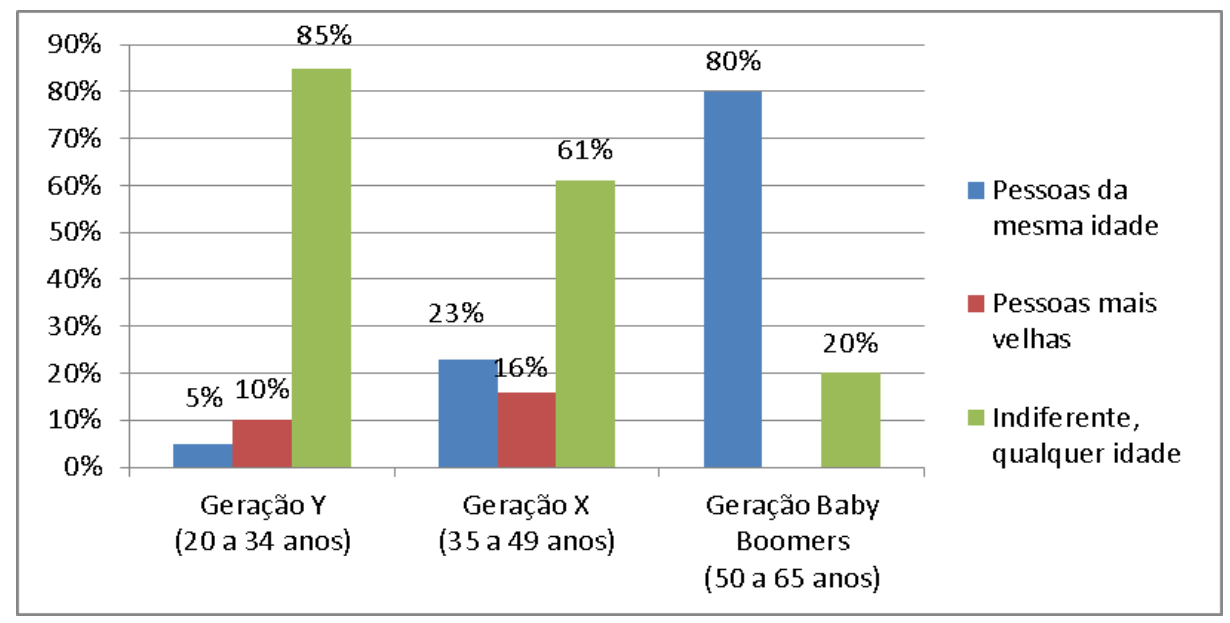

Fonte: Pesquisa de Campo.

No entanto as pessoas com idade entre 50 a 65 anos são os que mais possuem essa preferência, enquanto os de 20 a 34 anos não vê problema em trabalhar com pessoas de idades diferentes, o que indica que os mais novos devido a sua facilidade de adaptação não veem isso como um problema enquanto os mais velhos ainda resistem nessa questão, o que supostamente é devido ao fato dessas pessoas já estarem numa fase em que preferem se comunicar com pessoas que tendem a ter opiniões parecidas evitando assim possíveis conflitos.

\section{7- CONSIDERAÇÕES FINAIS}

O foco deste estudo foi evidenciar como os conflitos entre gerações podem ser mediados pelos gestores, em específico pelo gestor de Recursos Humanos, para isso buscou apresentar um breve histórico das gerações e seus comportamentos, assim como as características dos conflitos e sua interferência no cotidiano das organizações. Para reforçar e atender os objetivos do estudo apoiou-se em pesquisa de campo, que após análise dos resultados observou-se a necessidade real de tratar os conflitos, visto que os mesmos podem ter início através de pequenas causas, como preferência de relacionamento com determinadas pessoas ou pela falta de demonstração de adaptação e aderência as mudanças das organizações e do mercado de trabalho.

Outro ponto é que os profissionais das gerações estudadas estão cada vez mais se comportando com características próprias a cada uma, causando de certa forma uma barreira para os relacionamentos profissionais, assim como a competição por uma melhor colocação, visto que as 
exigências do mercado aumentaram. Houve de forma acelerada um grande aumento de pessoas qualificadas de todas as gerações desde a Geração Y até a Geração Baby Boomers, sendo que as pessoas dessa geração mesmo possuindo mais experiência tiveram que se adequar as mudanças para manterem seus empregos, já que seus cargos tornaram-se mais vulneráveis devido às novas exigências das organizações, que atualmente buscam além de experiência, conhecimento que agregue valor aos seus negócios.

Todos esses fatores demonstraram que os conflitos tendem a acontecer e que precisam ser tratados de forma adequada, e que a participação do gestor nesse processo torna-se fundamental já que sua figura é também responsável por manter o equilíbrio nas relações. O gestor de Recursos Humanos nesse caso, também possui papel fundamental, mesmo não lidando diretamente como todos os setores da empresa pode aplicar ações para identificar possíveis conflitos através de um entendimento mais aprofundado sobre os perfis dos profissionais, já que a organização é composta por diversas gerações que possuem comportamentos diferentes, conforme foi apresentado nesse estudo, e dessa forma mediar possíveis conflitos.

Enfim, a pesquisa realizada pôde demonstrar a importância de tratar os conflitos, entendendo quando são benéficos e quando são prejudiciais para os relacionamentos. Sugere-se como contribuição para novos estudos, pesquisar as expectativas da entrada da Geração Z no mercado de trabalho, geração esta que vem se desenvolvendo ligada diretamente aos meios tecnológicos e como a relação desta com as gerações existentes possivelmente se dará, se haverá choque de valores e conflitos ou se a convivência servirá como complemento para troca de conhecimentos, experiências e aprendizados.

Finalmente, ressalta-se que as organizações precisam entender que os conflitos geracionais fazem parte do seu cotidiano e que compreender seus comportamentos é necessário para manter o equilíbrio das relações, para que assim os profissionais independentes da geração, contribuam com o melhor de suas competências para o aprimoramento de conhecimentos e valores.

\section{REFERÊNCIAS}


ANDRADE, Rui Otávio Bernardes de; et. al. Princípios de Negociação - Ferramentas de Gestão. 2 ed. São Paulo: Atlas, 2011.

ASSIS, Jaqueline de et. al. As Relações no Gerenciamento Estratégico do Relacionamento entre Liderança $\quad$ e $\quad$ Geração $\quad$ Y. Sul, Chapecó, 2012. Disponível em:www.intercom.org.br/papers/regionais/sul2012/R30-1553-e Acesso em 30 jan.2014.

BANOV, Márcia Regina e FIDELIS, Gilson José. Gestão de Recursos Humanos - Tradicional e Estratégica. 2 ed. São Paulo:Érica, 2011.

BARDIN, Laurence. Análise de conteúdo. Lisboa: Edições 70, 1977.

BARROS, Jorge Pedro Dalledonne. Negociação. Rio de Janeiro: SENAC Nacional, 2009.

BOOG, Gustavo G, O choque das gerações Baby Boomers, X e Y: como sair desta? Disponível em: http://carreiras.empregos.com.br/comunidades/rh/colunistas/031109. Acesso em: 31 jan.2014.

CARVAlHAL, et. al. Negociação e Administração de Conflitos. 2. ed. Rio de Janeiro: FGV, 2009.

CARVAlHO, Antônio V. de; et. al. Administração de Recursos Humanos. v.1, 2 ed. São Paulo: Cengage Learning, 2012.

CHIAVENATO, Idalberto. Recursos Humanos: O capital das organizações. 9 ed. Rio de Janeiro: Elsevier, 2009.

CORDEIRO et. al. A questão das Gerações no campo da Gestão de Pessoas: tema emergente?XV SemeAD 2012. Disponível em:www.ead.fea.usp.br/semead/964.pdf.Acesso em: 30 mai. 2014. 
GIL, Antônio Carlos. Gestão de Pessoas. Enfoque nos papéis profissionais. São Paulo: Atlas, 2010.

GUALDI, Flávio Pereira. RAMOS, Kênia. FERNANDES, Kellia Jordana. TFS de PSICOLOGIA. Brasília, 2010 Disponível em: http://trabalhosderh.blogspot.com.br/2011/02/formas-de-poder-e-ascausas-dos.html. Acesso em: 30 mai. 2014.

LAKATOS, Eva Maria e MARCONI, Marina de Andrade. Fundamentos de Metodologia Científica. 7.ed.São Paulo:Atlas, 2010.

LOMBARDIA, Pilar García. Quem é a geração Y? HSM Management, n.70, p.1-7. set./out.2008

MARTINELli, Dante P. e ALMEIDA, Ana Paula de. Negociação e Solução de Conflitos. Do impasse ao ganha-ganha através do melhor estilo. São Paulo:Atlas, 2011.

NERY, Maria da Penha. Métodos Para a Administração de Conflitos. Disponível em: www.geocities.ws/relacoeshumanas/pages/artigos_admconflitos.htm. Acesso em: 31 jan.2014.

OLIVEIRA, Sidnei. Geração Y: Era das Conexões, Tempo de Relacionamentos. São Paulo: Clube de Autores, 2009.

ROBBINS, Stephen P. et al. Comportamento Organizacional.Teoria e prática no contexto brasileiro.14 ed. São Paulo: Pearson Prentice Hall, 2010.

SANTOS, Cristiane Ferreira dos; et. al. O processo evolutivo entre as gerações $\mathbf{X}$, Y e Baby Boomers. XIV SemeAd Seminários em Administração, 2011. Disponível em: www.ead.fea.usp.br/semead/221.pdf.Acesso em:15 abr.2014.

SPECTOR, Paul E. Psicologia nas Organizações. 3 ed. São Paulo: Saraiva, 2010. 
SERRANO, Daniel P. Geração Z.Disponível em:http://www.portadomarketing.com.br/artigo 3/Geração_Zhtm.Acesso em: 30 mai. 2014.

VASCONCELOS et. al. A Geração Y e suas Âncoras de Carreira. Revista eletrônica de Gestão Organizacional. Disponível em: www.revista.ufpe.br/gestaoorg/php/gestao/article/. Acesso em 15 fev.2014.

WEIL, Pierre. A Arte De Viver a Vida. 2 ed. Brasília: Letrativa Editorial, 2004.

WIELSEL, Gilberto. Geração Z: sustentáveis, exigentes e seus futuros clientes. Sua empresa está preparada?Disponível em: www.administradores.com.br/33541/.Acesso em:30 mai.2014

Recebido em: 18/04/2017

Aceito em: 28/05/2017

Endereço para correspondência:

Nome Renan Gomes de Moura

e-mail: renangmoura@gmail.com

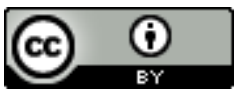

Este obra está licenciada com uma Licença Creative Commons Atribuição 4.0 Internacional. 